\title{
Practicing What You Preach: Evaluating Access of Open Access Research
}

By Teresa Auch Schultz

Scholarly Communications and Copyright Librarian

University of Nevada, Reno

teresas@unr.edu

Preprint manuscript 


\section{Abstract}

The open access movement seeks to encourage all researchers to make their works openly available and free of paywalls so more people can access their knowledge. Yet some researchers who study open access (OA) continue to publish their work in paywalled journals and fail to make it open. This project set out to study just how many published research articles about OA fall into this category, how many are being made open (whether by being published in a gold OA or hybrid journal or through open deposit), and how library and information science authors compare to other disciplines researching this field. Because of the growth of tools available to help researchers find open versions of articles, this study also sought to compare how these new tools compare to Google Scholar in their ability to disseminating OA research. From a sample collected from Web of Science of articles published since 2010, the study found that although a majority of research articles about OA are open in some form, a little more than a quarter are not. A smaller rate of library science researchers made their work open compared to non-library science researchers. In looking at the copyright of these articles published in hybrid and open journals, authors were more likely to retain copyright ownership if they printed in an open journal compared to authors in hybrid journals. Articles were more likely to be published with a Creative Commons license if published in an open journal compared to those published in hybrid journals.

\section{Introduction}

Over the past 15 years, research into open access $(O A)$ has grown from a smattering of articles looking at whether $\mathrm{OA}$ increases citations to a steady flow of research on a variety of issues connected to the field, including growth, economics, legal issues, and more (Rodrigues, Taga, and Passos 2016). A number of these articles have set out to determine how much of the overall research corpus is being made open, whether through open journals or open archiving. However, little has been done to look at OA researchers' own participation in OA.

OA advocates have anecdotally shared stories of stumbling upon articles about the field that are locked behind a paywall. At one point, Hull (2012) even proposed the Open Access Irony award highlight these. However, just one project has attempted to formally study this, focusing only on research about OA by library and information science (LIS) researchers (Grandbois and Beheshti 2014). None have set out to track the overall participation in OA by all authors researching the movement. This can be important considering the interdisciplinary nature of $\mathrm{OA}$ as a field. Librarians carved out a large role as early advocates, but OA is concerned with scholarly communication as a whole. Researchers from a broad array of fields have contributed their efforts to studying it (Miguel, Tannuri de Oliveira, and Cabrini Gracio 2016).

The study of OA has grown ever since the Budapest Open Access Initiative (2002) formulated a definition for the movement, one that stressed making scholarly works not only freely available online but also licensed for reuse. This definition included two major paths to OA: journals that publish articles as open, or gold OA, and scholarly works deposited in an open repository, also known as green OA. Suber (2008) has also posited another distinction: works that are simply made free (gratis) and works that are both free and licensed for reuse (libre). OA as a movement has seen a number of changes since these early definitions, including what's commonly known as hybrid journals, or journals that continue to charge a subscription but allow authors to pay a fee to make their article open. Each type of OA has 
come to constitute a share of the overall rate of $\mathrm{OA}$ in relation to the larger scholarly communication world.

\section{Literature review}

\section{Growth of Open Access}

A number of studies have looked at the growth of OA in the world of scholarly research, both broadly and by discipline. Bjork, Roos, and Lauri (2009) made one such early attempt by searching for green OA versions of articles published in 2006 and found they made up 11.3 percent of the research. A follow up of science research articles published in 2008 found a similar share (11.7 percent) for green OA articles. It went further, though, to discover the share gold OA articles (8.5 percent) among the study sample (Bjork et al. 2010). The authors found that a fifth of the articles in the study had been made open whether through green or gold OA.

A larger study - this time including 111,312 articles published in 2011 - found a much higher rate of green OA articles, 77.8 percent (Laakso and Bjork 2013). However, a review of such studies estimated that in 2014 green OA articles made up about 12 percent of scholarly research (Bjork et al. 2014).

Not all disciplines participate in OA at the same levels. Gargouri et al. (2012) looked at the rates for 14 specific disciplines. Looking at two batches of scholarly articles - those published between 1998 to 2006, and those published from 2005 to 2010 - the authors noted that the overall growth of OA participation grew from 20 percent of research articles published from 1998 to 2006 to 24 percent for articles published from 2005 to 2010 (Gargouri et al. 2012). Breaking their results down to specific disciplines, the authors found that mathematics had the highest rate of OA participation in both groups of articles (34 percent in the earlier group, 45 percent in the latter) (Gargouri et al. 2012). Clinical medicine had the lowest rate among the earlier group ( 3 percent), and the arts saw the lowest share among the latter group (10 percent) (Gargouri et al. 2012). Overall, most of the disciplines saw an increase in OA participation between the two batches (Gargouri et al. 2012). As Bjork et al. (2010) found, green OA appeared to be more common for the latter group of articles (21 percent of articles published in paywalled journals) than gold OA (2 percent of all articles) (Gargouri et al. 2012).

A study of LIS researchers found open versions for just 27 percent of the articles in the study sample (Way, 2010). The findings of that study appear perhaps lower than some would think as librarians have been among the earliest and strongest advocates for OA. Way notes that "In many ways, this involvement likely grew out of the principles of librarianship that align with the OA movement and at the same time out of necessity based on the crisis in scholarly communication that has led to increasing pressures on library budgets" (2010, p. 302). Mercer (2011) did find better rates (49 percent) of gold OA participation of academic librarians, finding librarians increasingly pursued OA as more OA journals became available.

However, a more recent survey of 1,017 LIS researchers found that although 80 percent had published in a paywalled journal in the past year, less than half of that (37 percent) reported publishing in an OA journal in the same time period (Peekhaus and Proferes 2015) Slightly more than half of the respondents (53 percent) had ever published in an OA journal, and half had ever deposited their work in an open repository (Peekhaus and Proferes 2015). Reasons librarians gave for not publishing OA included publishing fees, the belief that doing so took longer, concerns over prestige, and concerns of 
low impact (Peekhaus and Proferes 2015). Almost half of respondents (44 percent) also reported concerns that an OA article would meet with negative views from tenure and promotion committees (Peekhaus and Proferes 2015). In looking at positive factors, the article found that those who had already published OA were more likely to do so than those who had not, suggesting a familiarity with it was likely to encourage OA publishing (Peekhaus and Proferes 2015).

The "do as I say, not as I do" mentality can further be seen in Palmer, Dill, and Christie's (2009) survey of academic librarians and their attitudes toward OA. Librarians on average said they agreed with the idea that they should encourage faculty to self-archive their work but then reported only occasionally doing so themselves. The authors noted this dichotomy, writing "This survey found that agreement with various open access-related concepts does not constitute actual action" (Palmer et al. 2009). Dalton (2013) found that OA publishing did not rank high with LIS researchers, who ranked it as one of the lowest factors they considered in deciding where to publish. "Whilst a lack of awareness of the significance of open access publishing could be relevant in other disciplines, this should not affect librarians and information scientists, for whom OA is a fundamental and widely-supported concept" (Dalton 2013, p. 53).

A broader look at all researchers' attitudes toward OA found that a discipline's culture of self-archiving, a feeling of altruism, the promise of academic reward, and strong technical abilities all positively influenced whether researchers took part in OA (Kim 2010). Negative factors included concern about copyright, time and effort involved, and age (Kim 2010). The idea of altruism also came out in another, similar study of New Zealand researchers, where the top reason given to deposit their works was to ensure others had access to it (Cullen and Chawner 2011).

\section{Calls for OA Publishing}

Several researchers and even national organizations have heralded the idea that librarians in particular should take active part in OA. Hall et al. point to the American Library Association's Core Values, noting that they "...call for fostering the aspirations of others seeking entrance into the profession. It is difficult to do this with paywalls in place" $(2016$, p. 664). They go on to note that the Core Values also promote the idea that library resources should be free to all and it is "thus incongruous not to apply the same essential values the scholarly communication of librarianship" (Hall et al. 2016, p 664). Way argued that LIS researchers need to be more proactive, saying "If publishers do not allow self-archiving or accept addenda, authors then need to refuse to publish in those venues. It would be at that point that the availability of LIS literature would match the rhetoric of many of its practitioners, and the field could point to its own literature as a shining example of free and open access" (Way 2010, p. 308). The Association of College and Research Libraries (2016) also recently released a position statement on OA, encouraging librarians to not only publish in OA journals but to advocate on behalf of OA with publishers in their roles as editors and peer reviewers.

Although no broader group exists to represent all researchers of OA, informal calls for OA researchers to practice what they preach abound. This includes the aforementioned proposal for the Open Access Irony Awards, which argued "Sometimes the lack of access is deliberate, other times accidental - but the consequences are serious" (Hull 2012, para. 4). Eve questioned this negative view of OA researchers, however. He argued that to best spread the message of OA, researchers should stop preaching to the choir and thus should publish in paywalled journals (Eve, 2013). However, it should be noted that a majority of journal publishers do allow authors to openly deposit versions of their articles 
(SHERPA/ROMEO 2017). Thus, this does not preclude OA researchers from taking part in the field they study.

\section{Research about OA}

So far, just one study has attempted to look at whether OA researchers are heeding the call to practice what they preach, and it focused on LIS authors (Grandbois and Beheshti 2014). The study gathered articles published from 2003 to 2011 in English-language journals from a library science-specific database and deleted articles that did not have an LIS author for a total of 203 articles (Grandbois and Beheshti 2014). About 94 percent of them supported OA, but 40 percent of the articles remained behind a paywall, with 36 percent published in an OA journal and 24 percent openly archived (Grandbois and Beheshti 2014). The authors did not attempt to answer the reason for this gap but noted that "While most people recognize the need to save energy and recycle waste, it takes much more than just awareness to get them to change their habits on a large scale. It takes a combination of measures of many different kinds" (Grandbois and Beheshti 2014, p. 20).

Other studies have started to look at this burgeoning field from other viewpoints. Liu and Gang found that in the early days of OA research, LIS journals played a major role, publishing 54 percent of the articles (Liu and Gang 2005). A more recent study found that LIS journals continued to dominate the field, as Learned Publishing, DLIB and JASIS/JASIST were some of the most cited journals in OA articles, although other journals, including Nature, also ranked highly (Düzyol, Taskin, and Tonta 2010). Miguel et al. later (2016) identified Serials Librarian as the publisher of the most OA research articles published up until 2015, followed by Learned Publishing and JASIST, tied for second. Although the authors did not track actual OA participation, they did find that a majority of the journals OA researchers publish in allow for article deposit, arguing "Thus, it is observed that there is a concern from the authors in reconciling the theme under study and the type of journal chosen for the socialization of new knowledge generated in this subject" (Miguel et al. 2016).

Düzyol, Taskin, and Tonta (2010) found a steady growth in articles about OA, with just two published in 2000 and reaching a high of 62 articles in 2007 before seeing declines over the next few years. The most common areas of research in those articles included institutional repositories, OA journals, and the broader theme of scientific communication (Düzyol, Taskin, and Tonta 2010). Another study by Rodrigues et al. has further expanded on research themes and identified overviews as the most common at 28.2 percent, followed by perceptions of OA second at 21.6 percent, and economics of OA third at 13.3 percent (Rodrigues, Taga, and Passos 2016). The study shows that growth of OA was the most common research theme in 2014 and 2015 (Rodrigues, Taga, and Passos 2016).

\section{OA Finding Tools}

In the studies that searched for OA versions of articles, scholars tended to rely on Google and Google Scholar to find open versions (Lyons and Booth 2011; Antelman 2004; Wohlrabe and Birkmeier 2014; Bjork et al. 2010; Matsubayashi et al. 2009; Norris et al. 2008; Way 2010). Although researchers would sometimes use other tools as well, such as PubMed Central, OAlster, and OpenDOAR, the better results of Google and Google Scholar persuaded researchers to rely on them. For instance, Norris et al. (2008) reported that Google and Google Scholar found 86 percent of the open versions, whereas OAlster and OpenDOAR found just 14 percent. However, Way (2010) voiced concerns with Google Scholar after finding it failed to return articles published in gold OA journals. He did note that he continued to use it because so many researchers use it themselves (Way 2010). 
Several new tools have appeared in the past few years that offer themselves as alternatives specifically for finding free or open versions of articles. These include Lazy Scholar (LS), a Chrome extension that searches Google Scholar to let readers on a paywalled page for an article know if a free version is available; the Open Access Button (OAB), which uses both a website and a Chrome extension to let readers search for open articles; and Unpaywall, the newest offering, which also acts through a Chrome extension to search for open articles via the DOI. The OAB expands on its offering by also helping readers email the author to request an open version when one can't be found. Although it does not appear that any research projects have studied these new tools, they have still received support and recommendations, especially OAB and Unpaywall (Hooper 2017; Herron 2017 ; Gering 2017 ; Swoger 2013 ; Curry 2013).

\section{Methodology}

Because of the interdisciplinary nature of research into $O A$, this study was interested in looking at research from authors of all disciplines, not just those in LIS, as Grandbois and Beheshti (2014) did. To better ensure a broad field of authors, this study opted to search Web of Science (WOS), a database that includes most if not all disciplines, to build the study sample. As the study was also interested in more recent research, articles were limited to those published in 2010 and after.

\section{Collecting articles}

The first part of the study sample collection focused on finding articles published in paywalled journals. The study searched the term "open access" in the topic field and then filtered the results to remove articles that had been published as OA. This returned 10,265 articles. A quick examination showed that this was likely because WOS' OA filter failed to catch hybrid OA articles on other topics. Because of time constraints, the search was further filtered to include only articles published in LIS journals, which returned 521 articles.

To ensure that the study sample did not focus too much on LIS research, a second search was performed limiting the search for "open access" to titles only. Using the same parameters as the first search except for limiting to any journal subject, this search returned 525 articles not found in the first search. These 1,046 articles constituted the initial study sample of articles about OA published in a paywalled journal.

Metadata for the articles from both searches were exported into a spreadsheet. Titles and abstracts for the articles were checked to see if the articles were actually related to the study of OA. The study deleted articles if they referred to OA in another concept (such as open access fisheries), if OA was only a tangential part of the study, or if it was not clear. After this filtering, 526 articles remained in the study sample.

The second part of the search focused on finding articles published in gold OA journals. It followed a similar method as the previous steps, although this time filtering the WOS' results to include only articles published as OA. This resulted in 164 articles.

As stated before, WOS' OA filter is not perfect, grouping hybrid OA articles in with paywalled articles. Whenever these errors were found, the study moved the articles to the appropriate category. 


\section{OA finding tools}

To explore the effectiveness of the new OA finding tools, the next step of the study used the Chrome extensions for Google Scholar, Lazy Scholar (LS), Unpaywall, and the Open Access Button (OAB) to look for green OA versions of paywalled articles. All four were used on each article, and the study tracked to see how many open articles each one found. The study also tracked how many times LS, Unpaywall, and $O A B$ returned false positives (such as when the resulting webpage showed an error message). Google Scholar was not included in this part of the search as it does not purport to find only open versions of articles.

Searches for open versions of paywalled articles were performed away from the author's university to ensure the institution's subscriptions to various journals did not impact results.

Although the study considered incorporating $O A B^{\prime}$ 's other feature - sending emails to authors of paywalled articles to request they deposit the article so it is open - technical issues and limited time meant that this was dropped from the study.

The study also tracked the discipline of the first author of every article in the study sample and did so first by checking author information in the article and then, if needed, searching the web for more information. If the author's discipline could not be found or was unclear, it was marked as such.

Finally, the study also tracked the copyright owner for each article and whether an article was gratis or libre (for articles published in gold and hybrid journals). This information was collected from the article and, if not available there, from the journal's website. If the copyright owner was not clear, it was marked as such. If it was not clear if an article was licensed for reuse, the article was marked as being gratis.

All data collection for this study took place in April 2017.

\section{Issues with methodology}

Although WOS includes a wide coverage in terms of disciplines, it is limited in that it is selective of what journals it includes, aiming for what it considers the best (Testa, 2016). Using only this database to collect articles therefore excluded any research articles about OA that were not published in these journals. However, time constraints prevented a wider search and consideration of more articles, and as WOS has a reputation for carrying most if not all of the traditional prestige journals, which are often a big draw for those seeking tenure and promotion, it was decided that the database would suit the purposes of this study. Other databases, such as Academic Search Premiere or even Google Scholar, could be used to find more articles.

Another issue with this methodology is it might have missed some green OA versions of articles, even with using these four search tools. Although studies have found Google Scholar to be one of the most effective ways of searching for open versions, Way (2010) has shown it is not perfect. Therefore, it is possible that this study undercounted the number of green $\mathrm{OA}$ articles. 


\section{Results}

\section{Proportion of open availability}

When looking at the entire study sample $(\mathrm{N}=609)$, articles published in gold OA journals made up the largest portion with 31.7 percent (193 articles), followed by green OA articles at 27.6 percent (168 articles). Paywalled articles made up 26.3 percent of the sample (160 articles), and hybrid OA articles made up 14.4 percent ( 88 articles) (Figure 1).

Dividing the articles by those published as open and those published behind a paywall, 53.9 percent were published in a paywalled journal, and 46.1 percent were published as open. Of the articles published behind a paywall, 51.2 percent were later deposited and made open. Of the articles published as open, 68.7 percent were published in a gold OA journal.

Although not constant, the number of articles about OA has increased over time, including when broken down by whether published in a paywalled, hybrid, or open journal. (Figure 2).

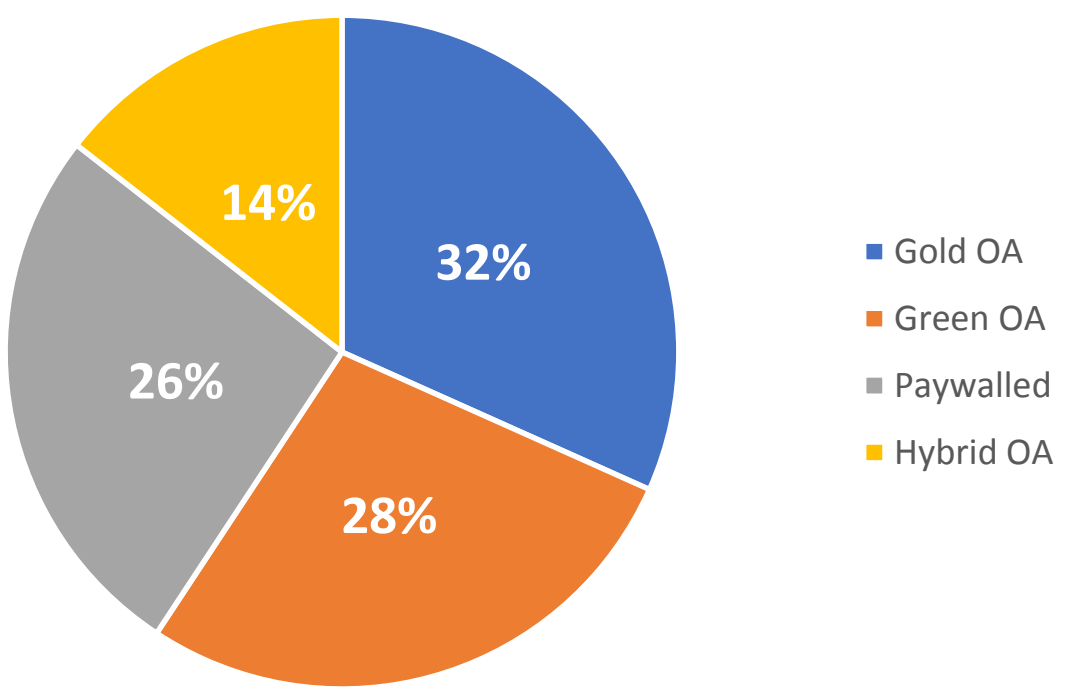

Figure 1. All articles broken down by type. 


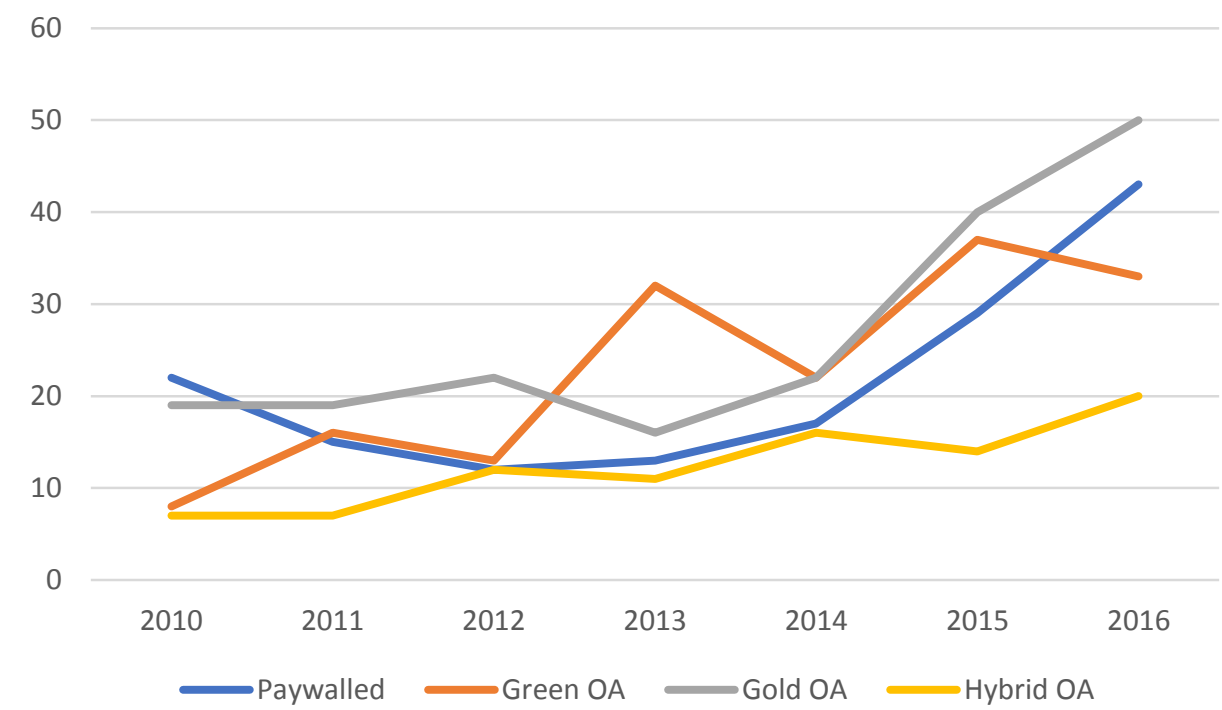

Figure 2. Articles by year published broken down by type. This does not include articles published in 2017.

\section{Author Disciplines}

Although the study tracked each first author's field of study, there were so many (ranging from various fields in the sciences, social sciences, and humanities) that most fields had less than a handful of authors. The study was also concerned with incorrectly labeling some authors, as it was clear they came from an interdisciplinary background. Instead of dividing each author up by their respective disciplines, then, this study opted to compare LIS researchers to non-LIS researchers.

LIS researchers made up the largest contingent of any discipline, serving as the first author for 225 articles in the study sample (36.9 percent) (Figure 3). Within articles with an LIS first author, 29.3 percent were paywalled with no open option available, compared to 25.6 percent of articles with a nonLIS first author. A greater share of non-LIS authors also published in open journals (35.5 percent of articles published by non-LIS first authors) than did LIS first authors (26.7 percent of articles by LIS researchers) (Figure 4). A chi-square test found a $p$ value of .032 when comparing the differences in OA rates between LS and non-LS researchers, meaning the evidence strongly supports a statistical significance in their differences. 


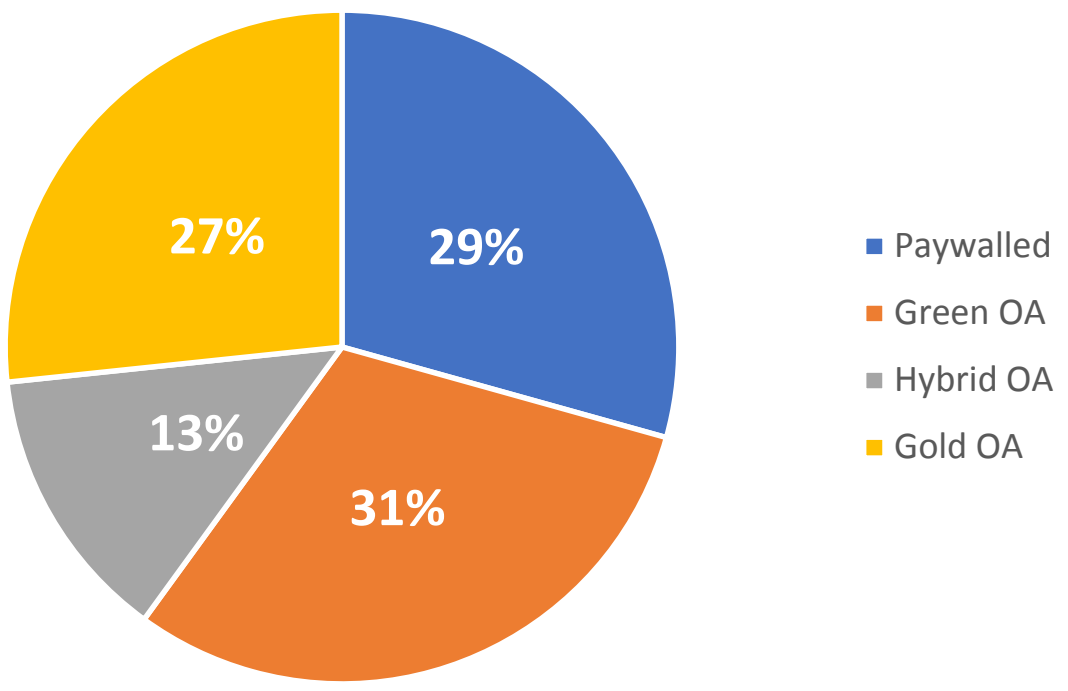

Figure 3. Articles with an LIS researcher as first author.

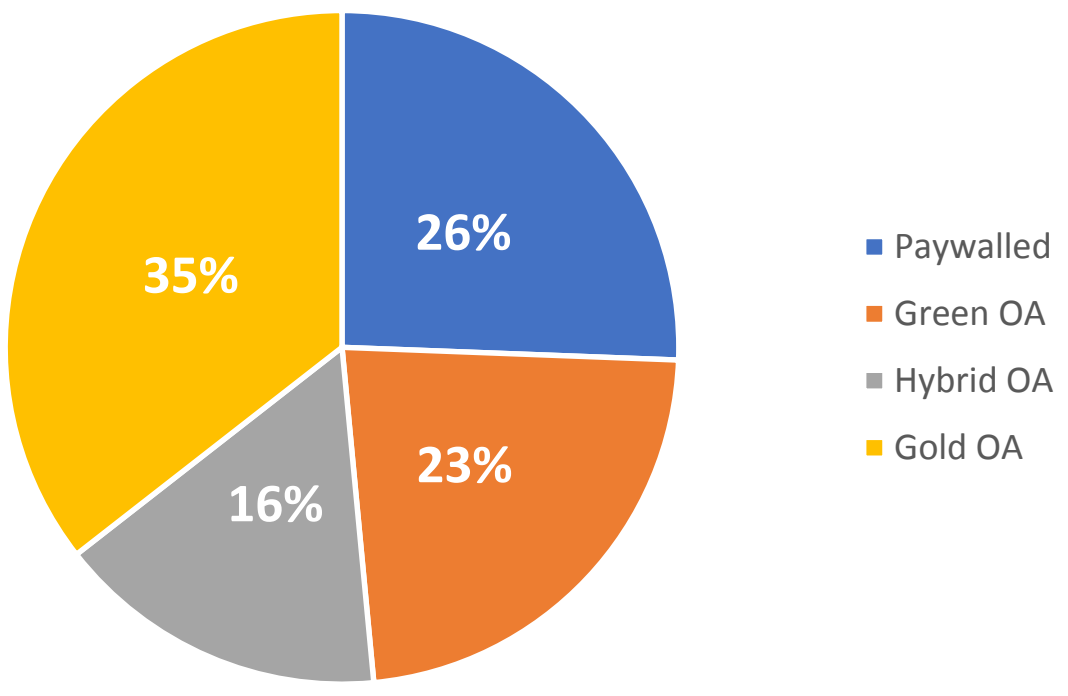

Figure 4. Articles with a non-LIS researcher as first author.

\section{Copyright}

Authors were more likely to retain copyright when they published in gold OA journals, with almost two thirds (64.2 percent) doing so, compared to 58 percent of authors publishing in hybrid journals (Figure 5). Publishers owned the copyright in 18.1 percent of articles published in gold OA journals and in 19.3 percent of hybrid articles. There was one instance of the author and publisher sharing ownership to copyright in an open journal.

Breaking down copyright ownership by author discipline, LIS researchers retained ownership in 66.7 percent of their articles, and non-LIS researchers retained ownership in 63.2 percent of their articles. A chi-square test comparing these variables returned a $p$ value of .122, so it does not appear to be a statistically significant finding. 
Of hybrid articles, 70.5 percent appeared only to be gratis, lacking any indication of reuse. Just 29.5 percent appeared to be libre, whether through some notice of allowed reuse by the journal or a Creative Commons license. In contrast, 80.8 percent of articles published in gold OA journals were libre, usually by incorporating a Creative Commons license (Figure 6). Just 17.1 percent of these articles appeared to be gratis. Four of the articles published in College \& Research Libraries, now an gold OA journal, were published before the journal began using Creative Commons licenses and thus are only freely available although published in a now-open journal.

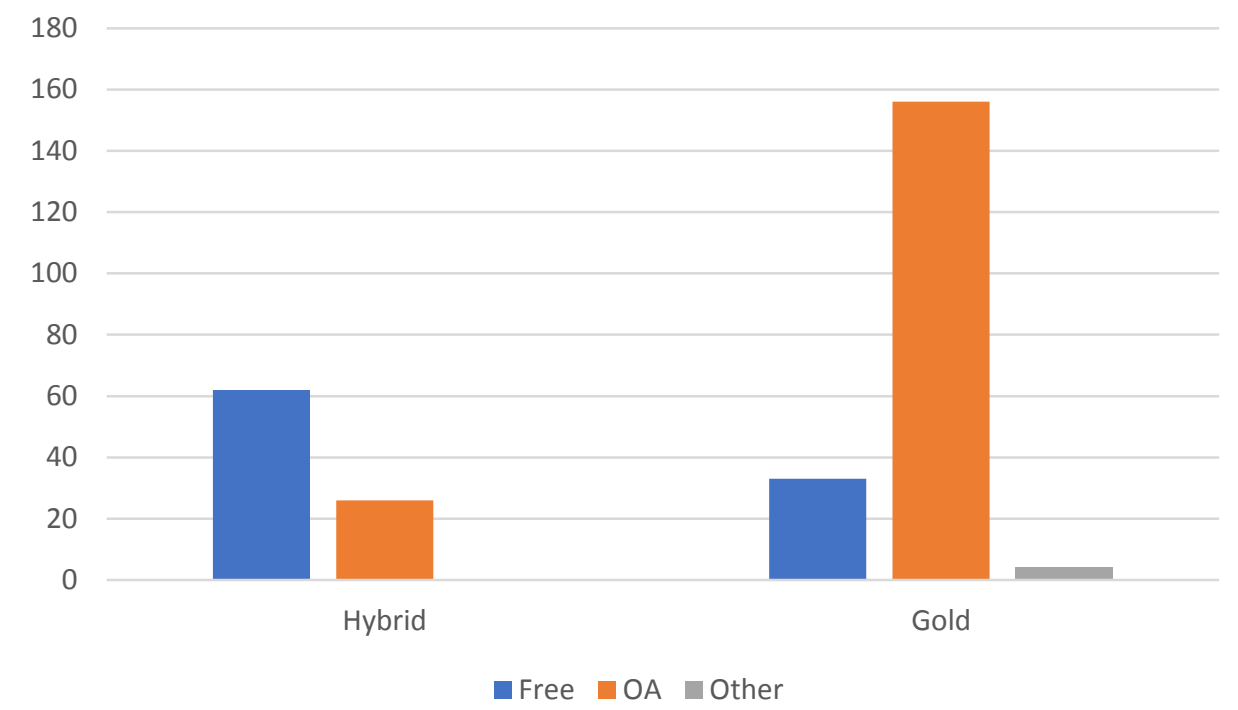

Figure 5. The number of hybrid and gold $O A$ articles that were published for free with no reuse licensing and those published as both free and licensed for reuse.

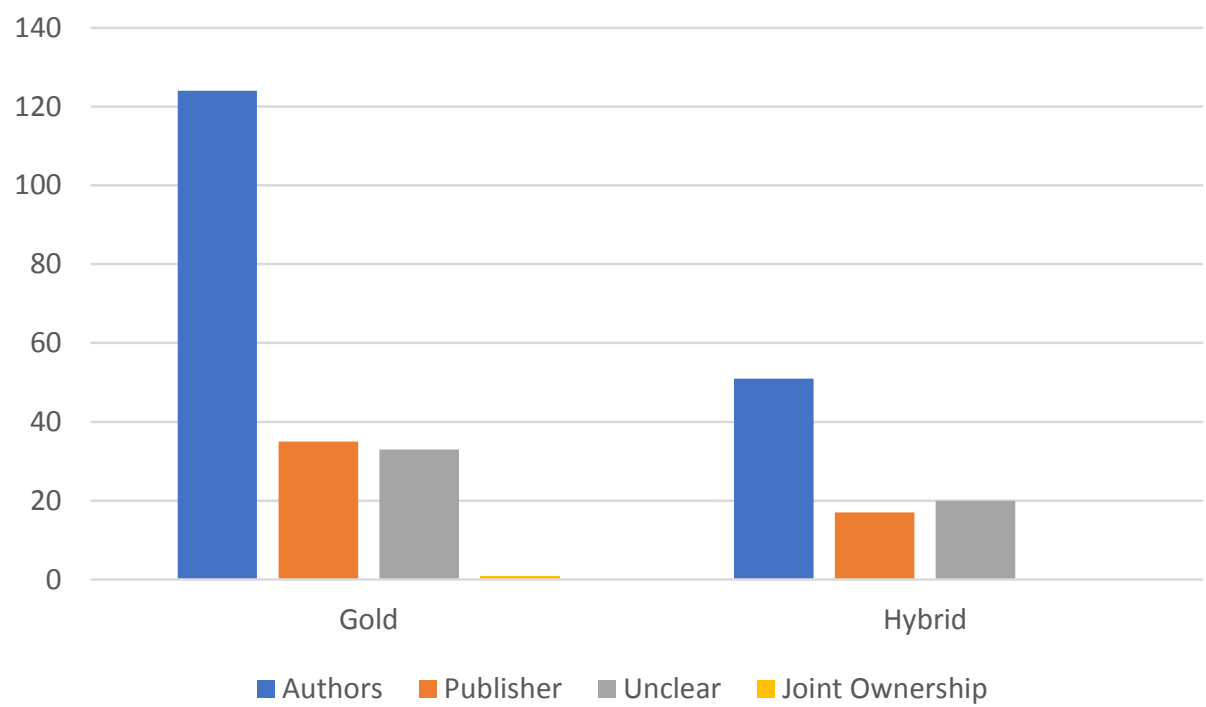

Figure 6. The number of gold and hybrid OA articles in which the author owns the copyright, publisher does, it's unclear, or both own. 


\section{Search Tools}

Although Lazy Scholar, Unpaywall and the Open Access Button (OAB) all found a number of open versions of the study sample, Google Scholar returned the most (174) (Figure 7). It also found more open versions when none of the others did (22) (Figure 8). However, of the 160 green OA articles found, all but 33 were found by more than one of the tools.

The $O A B$ returned the most false positives with 35, while Unpaywall returned the second most with 20, and Lazy Scholar returned 10 (Figure 9).

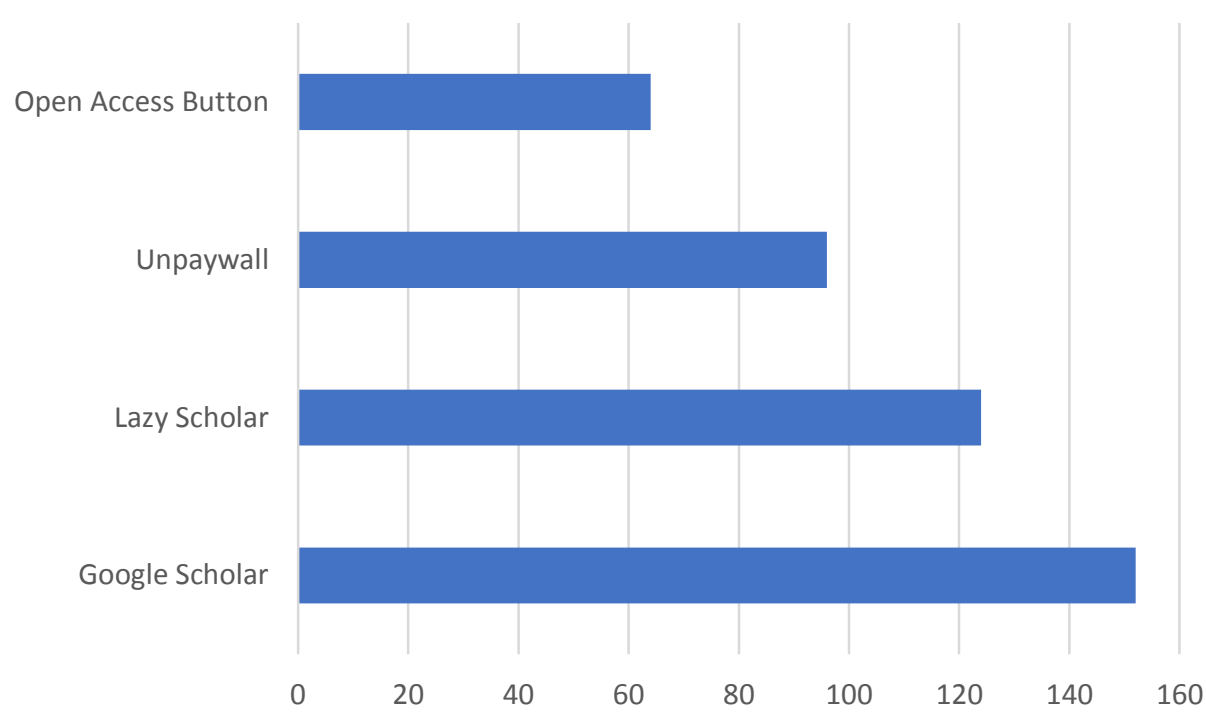

Figure 7. The number of articles each tool successfully found. Although there were just 160 green OA articles, an article was often found by multiple tools.

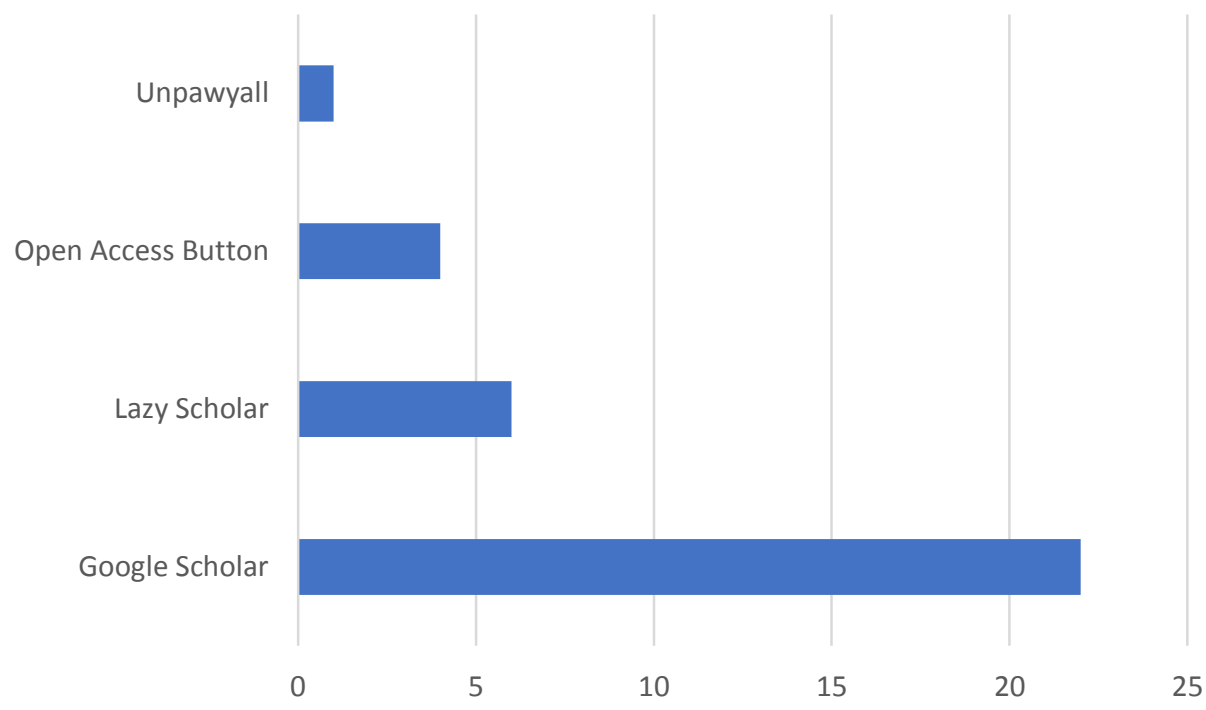

Figure 8. The number of articles for each search tool where that tool was the only one to find an open version. 


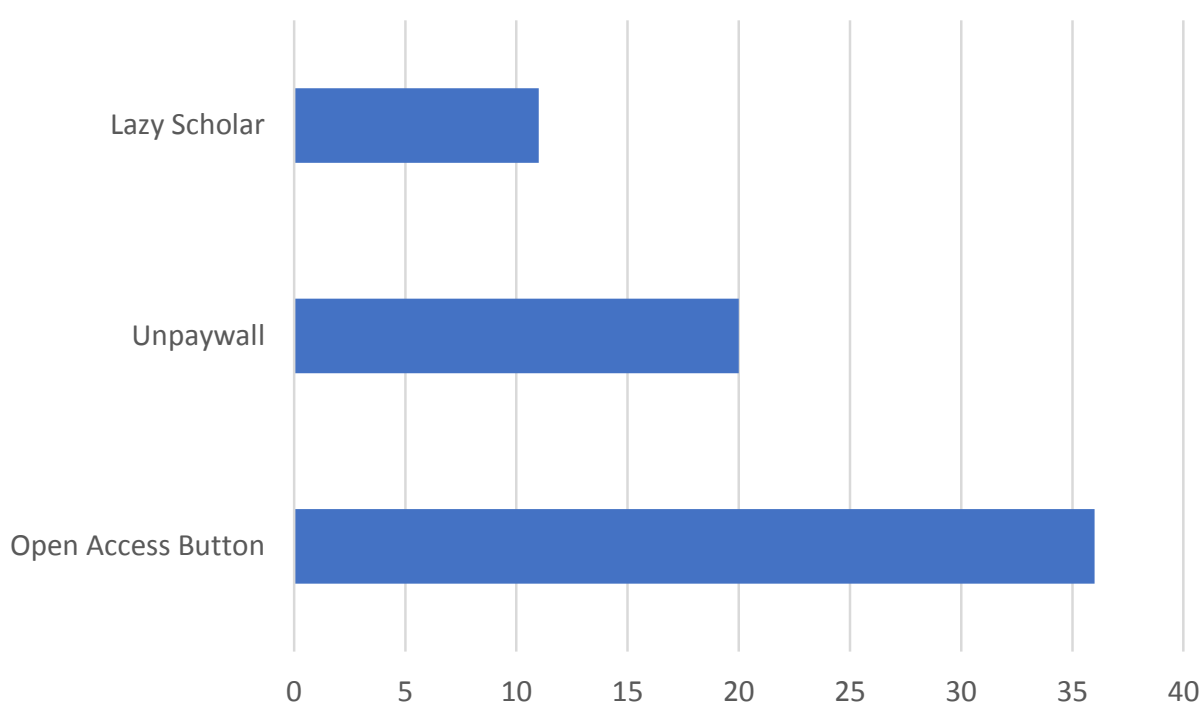

Figure 9. The number of false positives found by the search tools.

\section{Discussion}

The study sample size was triple the amount of articles that Grandbois and Beheshti (2014) found in their study. This is likely due in part to two factors: The study included all OA researchers, not just from the field of library science, and the amount of research into OA has grown in the past seven years in contrast to the first years of OA research.

This study's finding of an OA participation rate of 73.7 percent shows an improvement from the findings of Grandbois and Beheshti (2014), who saw an OA participation rate of just 60 percent. The improvement appears to hold true even when focused on just the LIS-led articles in this study, where 70 percent of articles were open in some way. This rate is also quite larger than the 27 percent rate that Way (2010) found for all librarian researchers. However, librarians still trailed other researchers in making their articles open by about four percentage points. Non-LIS researchers were also more likely to publish in a gold OA journals compared to LIS researchers.

As a whole, OA researchers participated in their field at among the highest rates found in other studies of OA participation in general (Laakso and Bjork 2013). They also took part in green OA at a higher rate than Bjork et al.'s (2014) estimate of 12 percent for scholarship in general.

As Grandbois and Beheshti (2014) found, the growth of participation in OA continues to go up over time, although these findings reflect that green OA has not seen such a smooth path in recent years. This could partly be caused by embargoes still in effect. Indeed, Grandbois and Beheshti (2014) purposely limited their study sample to those published in 2011 or prior to allow for any possible embargoes to run out. However, other studies have shown that authors don't follow journal deposit policies and will post copies of their work to open repositories in violation of them (Jamali 2017; Atchison and Bull 2015; Schultz 2017).

Some of the arguments in favor of OA and against the paywalled journal model have involved copyright ownership. Paywalled journals have traditionally required authors to transfer their copyright ownership, and OA advocates have argued that OA allows authors to keep their copyright (Tennant et al. 2016). 
However, that isn't always the case, and certainly not for OA researchers as shown by the evidence. At least some articles published in both gold $O A$ and hybrid journals required the author to transfer copyright. It is interesting to note that this was far more frequent for articles appearing in hybrid journals, which have been found to charge authors more on average for article processing charges (Wellcome Trust 2016).

Articles published in hybrid journals were also much more likely to publish the article simply as gratis vs. gold OA journals, which were far more likely to publish them as libre. OA researchers who opt to go the hybrid route, then, seem to be paying for less than those who go the gold OA route.

Finally, the results for the OA search tools show that while all three new options met with some success, none of them performed as well as Google Scholar. It is important to note that OAB, which found the fewest open versions, does not search ResearchGate and Academia.edu because of legal concerns over article versions that are likely infringing copyright, which the other tools do (Open Access Button 2017). This likely affected OAB's results. And while none of the tools performed as well as Google Scholar, each features an increase of ease of use over Google Scholar. LS and Unpaywall appear (for the most part) automatically, meaning users only have to click a button to be taken to an open version of the article if it's available. Users of OAB need only click a button on their tool bar to activate it. Even though Google Scholar does have a Chrome extension, meaning you do not need to open a separate page to search it, users must still type in their search query. Relying on LS, Unpaywall and/or OAB first causes them no harm, and they can always rely on Google Scholar as a backup. Whether all three tools are needed is unclear, especially if they could create a better tool by combining their resources.

\section{Conclusion}

In some respects, an OA participation rate of 73.7 percent shows a robust participation by OA researchers in their field of study. It's better than in most, if not all, other disciplines, and appears to show an increase in OA participation compared to that found by Grandbois and Beheshti (2014). The rate for these articles could also continue to go up in the next year or two as any embargoes run out and authors are then allowed to deposit their articles.

At the same time, if any researcher should be expected to take part in OA, many would think it should be those who are researching the very topic. This is especially true for LIS researchers, who are often some of the biggest advocates for OA. Indeed, Vandergrift and Bowley call on them to "practice what we preach, regardless of, or even in the face of, tenure and promotion 'requirements,' long-held professional norms, and the unnecessary fear, uncertainty and doubt that control academic publishing" (Vandergrift and Bowley 2014, para. 27).

And yet, despite showing improvements since the findings by Grandbois and Beheshti, they still trailed other researchers in making their research open. In that view, they still have a ways to go. How can we expect librarians in general, let alone the wider world of academia, to practice OA if those who make it the focus of their research continue to keep their articles paywalled? The fact that LIS researchers also trailed non-LIS researchers in publishing in gold OA journals is especially problematic concerning that most gold OA LIS journals do not charge a publishing fee (Directory of Open Access Journals 2017). One can also argue publishing in journals that require embargo periods damages the field by restricting access to those researchers who might not have access to paywalled journals. 
Also of interest is the number of open articles that are only available as gratis, vs. libre, and the number of articles in which the authors transferred copyright ownership. Although the OA community has often debated how restrictive the definition of OA should be, many call for at least some type of reuse licensing. For instance, the Open Access Scholarly Publishers Association's membership criteria strongly encourages a Creative Commons Attribution license and requires that OA journals' license policy "should allow for the broadest re-use of published material possible" (2017). However, it seems at least some journals - especially hybrid journals - are resisting these calls, which is especially concerning in light of how expensive the article processing charges for hybrid journals can be. OA researchers are likely paying more for less when they go the hybrid route.

Although the study showed that Google Scholar uncovered more articles than any of the other tools, those tools' utility can still be seen in that each one found articles not discovered by the other tools, including Google Scholar. Indeed, using the tools in conjunction with each other appears to be the best method. And although OAB found the fewest, the tool is a good candidate for anyone concerned about legal issues - such as interlibrary loan departments - because it does not search ResearchGate and Academia.edu, which often include infringing copies of articles.

This study attempted to provide an initial overview of how much of all the research on OA is actually being made open. Future areas of study include studying motivations of the authors in making or not making their work open, including whether these motivations reflect those found among other researchers and how much publisher policies affect author behaviors. Researchers can also continue to look at this longitudinally to see if the OA participation rate improves or declines in the future. In regards to OA finding tools, future study can study the effectiveness of the OAB's author emailing tool. 
References

Antelman, Kristin. 2004. "Do Open-Access Articles Have a Greater Research Impact?" College \& Research Libraries 65 (5): 372-382. http://crl.acrl.org/index.php/crl/article/view/15683/17129

Association of College and Research Librarians. 2016. “ACRL Issues New Policy Statement on Open Access to Scholarship by Academic Librarians." American Library Association. http://www.ala.org/news/press-releases/2016/07/acrl-issues-policy-statement-open-accessscholarship-academic-librarians

Atchison, Amy, and Jonathan Bull. 2015. "Will Open Access Get Me Cited? An Analysis of the Efficacy of Open Access Publishing in Political Science." PS: Political Science \& Politics 48 (01): 129-137. doi:10.1017/S1049096514001668

Auch Schultz, Teresa. 2017. “Open Up Communication: Assessing Open Access Practices in the Communication Studies Discipline." Journal of Librarianship and Scholarly Communication 5 (1). doi:10.7710/2162-3309.2131

Bjork, Bo-Christer, Annikki Roos, and Mari Lauri. 2009. "Scientific Journal Publishing: Yearly Volume and Open Access Availability." Information Research 14 (1). http://InformationR.net/ir/141/paper391.html

Björk, Bo-Christer, Patrik Welling, Mikael Laakso, Peter Majlender, Turid Hedlund, and Guđni Guðnason. 2010. “Open Access to the Scientific Journal Literature: Situation 2009.” PLOS ONE 5 (6): e11273. doi:10.1371/journal.pone.0011273.

Björk, Bo-Christer, Mikael1 Laakso, Patrik Welling, and Patrik Paetau. 2014. “Anatomy of Green Open Access." Journal of the Association for Information Science \& Technology 65 (2): 237-50. doi:10.1002/asi.22963.

Bowley, Chealsye, and Micah Vandergrift. 2014. “Librarian, Heal Thyself: A Scholarly Communication 
Analysis LIS Journals." In the Library with the Lead Pipe.

http://www.inthelibrarywiththeleadpipe.org/2014/healthyself/

Budapest Open Access Initiative. 2002. "Read the Budapest Open Access Initiative."

http://www.budapestopenaccessinitiative.org/read

Cullen, Rowena, and Brenda Chawner. 2011. "Institutional Repositories, Open Access, and Scholarly Communication: A Study of Conflicting Paradigms." The Journal of Academic Librarianship 37 (6): 460-70. doi:10.1016/j.acalib.2011.07.002.

Curry, Stephen. 2013. "Push Button for Open Access." The Guardian. https://www.theguardian.com/science/2013/nov/18/open-access-button-push

Dalton, Michelle. 2013. “A Dissemination Divide? The Factors That Influence the Journal Selection Decision of Library \& Information Studies (LIS) Researchers and Practitioners." Library and Information Research 37 (115): 33-57.

http://www.lirgjournal.org.uk/lir/ojs/index.php/lir/article/view/553/604

Directory of Open Access Journals. (2017). "Search."

https://doaj.org/search?source=\%7B\%22query\%22\%3A\%7B\%22filtered\%22\%3A\%7B\%22filter\%2 2\%3A\%7B\%22bool\%22\%3A\%7B\%22must\%22\%3A\%5B\%7B\%22term\%22\%3A\%7B\%22_type\%22\% 3A\%22journal\%22\%7D\%7D\%2C\%7B\%22term\%22\%3A\%7B\%22index.classification.exact\%22\%3A \%22Bibliography.\%20Library\%20science.\%20Information\%20resources\%22\%7D\%7D\%5D\%7D\%7 D\%2C\%22query\%22\%3A\%7B\%22match_all\%22\%3A\%7B\%7D\%7D\%7D\%7D\%2C\%22from\%22\%3A 0\%2C\%22size\%22\%3A10\%7D\#.WWhJ74jys2w

Düzyol, Güleda, Zehra Taşkın, and Yaşar Tonta. 2010. “Mapping the Intellectual Structure of the Open Access Field Through Co-Citation Analysis." Presented at the IFLA Satellite Preconference: Open Access to Science Information Trends, Models and Strategies for Libraries, Crete, Greece. http://eprints.rclis.org/14910/. 
Enis, Matt. 2017. “Impact Story Launches Browser Extension for OA Discovery.” Library Journal. http://lj.libraryjournal.com/2017/04/oa/impactstory-launches-browser-extension-for-oadiscovery/

Eve, Martin Paul. 2017. "How ironic are the open access irony awards?" https://www.martineve.com/2013/10/21/how-ironic-are-the-open-access-irony-awards/. Gargouri, Yassine, Vincent Larivière, Yves Gingras, Les Carr, and Stevan Harnad. 2012. “Green and Gold Open Access Percentages and Growth, by Discipline." http://arxiv.org/abs/1206.3664.

Gering, E.E. 2017. “Review: Unpaywall.” https://eegering.wordpress.com/2017/05/24/reviewunpaywall/

Grandbois, Jennifer, and Jamshid Beheshti. 2014. "A Bibliometric Study of Scholarly Articles Published by Library and Information Science Authors about Open Access." Information Research: An International Electronic Journal 19 (4). https://eric.ed.gov/?id=EJ1050457.

Hall, Nathan, Sara Arnold-Garza, Regina Gong, and Yasmeen Shorish. 2016. "Leading by Example? ALA Division Publications, Open Access, and Sustainability." College \& Research Libraries 77 (5): 65467. doi:10.5860/crl.77.5.654.

Herron, Matthew. 2017. "Two More Tools for (Legally) Avoiding Paywalls." Free Thought Blogs. http://freethoughtblogs.com/fierceroller/?p=2498

Hull, Duncan. 2012. "The Open Access Irony Awards: Naming and Shaming Them." https://duncan.hull.name/2012/02/15/open-irony/

Jamali, Hamid R. 2017. “Copyright Compliance and Infringement in ResearchGate Full-Text Journal Articles." Scientometrics, February, 1-14. doi:10.1007/s11192-017-2291-4.

Kim, Jihyun. 2010. "Faculty Self-Archiving: Motivations and Barriers." Journal of the American Society for Information Science and Technology 61 (9): 1909-22. doi:10.1002/asi.21336. 
Laakso, Mikael, and Bo-Christer Björk. 2013. “Delayed Open Access: An Overlooked High-Impact Category of Openly Available Scientific Literature." Journal of the American Society for Information Science and Technology 64 (7): 1323-1329.

Liu, Zao, and Wan Gang. 2017. "Scholarly Journal Articles on Open Access in LIS Literature: A Content Analysis." Chinese Librarianship: An International Electronic Journal, 23. http://www.iclc.us/cliej/cl23LiuWan.htm

Lyons, Charles, and H. Austin Booth. 2011. "An Overview of Open Access in the Fields of Business and Management." Journal of Business \& Finance Librarianship 16 (2): 108-24. doi:10.1080/08963568.2011.554786.

Matsubayashi, Mamiko, Keiko Kurata, Yukiko Sakai, Tomoko Morioka, Shinya Kato, Shinji Mine, and Shuichi Ueda. 2009. "Status of Open Access in the Biomedical Field in 2005." Journal of the Medical Library Association : JMLA 97 (1): 4-11. doi:10.3163/1536-5050.97.1.002.

Mercer, Holly. 2011. "Almost Halfway There: An Analysis of the Open Access Behaviors of Academic Librarians." College \& Research Libraries 72 (5): 443-53. doi:10.5860/crl-167.

Miguel, Sandra, Ely Tannuri de Oliveira, and Maria Cabrini Grácio. 2016. "Scientific Production on Open Access: A Worldwide Bibliometric Analysis in the Academic and Scientific Context." Publications 4 (1): 1. doi:10.3390/publications4010001.

Norris, Michael, Charles Oppenheim, and Fytton Rowland. 2008. "The Citation Advantage of OpenAccess Articles." Journal of the American Society for Information Science and Technology 59 (12): 1963-72. doi:10.1002/asi.20898.

Open Access Button. 2017. "Open Access Button Library Service FAQ." https://docs.google.com/document/d/1_HWKrYG7Qj7ff05cx8Kw40mL7ExwRz6ks5Fb10GEGg/edit

Palmer, Kristi L., Emily Dill, and Charlene Christie. 2009. “Where There's a Will There's a Way?: Survey of 
Academic Librarian Attitudes about Open Access." College \& Research Libraries 70 (4): 315-35. doi:10.5860/crl.70.4.315.

Peekhaus, Wilhelm, and Nicholas Proferes. 2015. "How Library and Information Science Faculty Perceive and Engage with Open Access." Journal of Information Science 41 (5): 640-61. doi:10.1177/0165551515587855.

Rodrigues, Rosângela Schwarz, Vitor Taga, and Mariana Faustino dos Passos. 2016. "Research Articles about Open Access Indexed by Scopus: A Content Analysis." Publications 4 (4): 31. doi:10.3390/publications4040031.

SHERPA/RoMEO. 2017. "RoMEO Statistics." http://www.sherpa.ac.uk/romeo/statistics.php?la=en\&fIDnum=|\&mode=simple Suber, Peter. 2008. "Gratis and Libre Open Access." SPARC. https://sparcopen.org/our-work/gratis-andlibre-open-access/

Swoger, Bonnie. 2013. "The Open Access Button: Discovering When and Where Researchers Hit Paywalls." Scientific American. https://blogs.scientificamerican.com/information-culture/theopen-access-button-discovering-when-and-where-researchers-hit-paywalls/

Tennant, Jonathan P., François Waldner, Damien C. Jacques, Paola Masuzzo, Lauren B. Collister, and Chris. H. J. Hartgerink. 2016. “The Academic, Economic and Societal Impacts of Open Access: An Evidence-Based Review." F1000Research 5 (April): 632. doi:10.12688/f1000research.8460.1. Testa, James. 2016. "The Web of Science Journal Selection Process." Web of Science. http://wokinfo.com/essays/journal-selection-process/

Way, Doug. 2010. "The Open Access Availability of Library and Information Science Literature." College \& Research Libraries 71 (4): 302-309. doi:10.5860/crl-38r1

Wellcome Trust. 2017. "Wellcome and COAF Open Access Spend 2015-16." 
https://wellcome.ac.uk/funding/managing-grant/wellcome-and-coaf-open-access-spend-2015-

16

Willi Hooper, Michaela D. 2017. "Product Review: Unpaywall.” Journal of Librarianship and Scholarly Communication 5 (1). doi:10.7710/2162-3309.2190

Wohlrabe, Klaus, and Daniel Birkmeier. 2014. "Do Open Access Articles in Economics Have a Citation Advantage?" https://mpra.ub.uni-

muenchen.de/56842/?utm_content=buffer6d221\&utm_medium=social\&utm_source=twitter.c om\&utm_campaign=buffer. 